\title{
Bridging the Gap: Self-Directed Staff Technology Training
}

Undergraduates, as members of the Millennial Generation, are proficient in Web 2.0 technology and expect to apply these technologies to their coursework-including scholarly research. To remain relevant, academic libraries need to provide the technology that student patrons expect, and academic librarians need to learn and use these technologies themselves. Because leaders at the Harold B. Lee Library of Brigham Young University (HBLL) perceived a gap in technology use between students and their staff and faculty, they developed and implemented the Technology Challenge, a self-directed technology training program that rewarded employees for exploring technology daily. The purpose of this paper is to examine the Technology Challenge through an analysis of results of surveys given to participants before and after the Technology Challenge was implemented. The program will also be evaluated in terms of the adult learning theories of andragogy and selfdirected learning. HBLL found that a self-directed approach fosters technology skills that librarians need to best serve students. In addition, it promotes lifelong learning habits to keep abreast of emerging technologies. This paper offers some insights and methods that could be applied in other libraries, the most valuable of which is the use of self-directed and andragogical training methods to help academic libraries better integrate modern technologies.

eaders at the Harold B. Lee Library of Brigham Young University (HBLL) began to suspect a need - for technology training when employees were asked during a meeting if they owned an iPod or MP3 player. Out of the twenty attendees, only two raised their hands-one of whom worked for IT. Perceiving a technology gap between HBLL employees and student patrons, library leaders began investigating how they could help faculty and staff become more proficient with the technologies that student patrons use daily. To best serve student patrons, academic librarians need to be proficient with the technologies that student patrons expect. HBLL found that a self-directed learning approach to staff technology training not only fosters technology skills, but also promotes lifelong learning habits.

To further examine the technology gap between librarians and students, the HBLL staff, faculty, and student employees were given a survey designed to explore generational differences in media and technology use. Student employees were surveyed as representatives of the larger student body, which composes the majority of HBLL patrons. As anticipated, results indicated that students frequently use text messages, social networks, blogs, etc., while fewer staff members use these technologies. For example, 42 percent of the students reported that they write a blog, while only 26 percent of staff and faculty do so. Also, 74 percent of the students and only 30 percent of staff and faculty indicated that they belonged to a social network. After concluding that staff and faculty were not as connected as their student patrons are to technology, library administration developed the Technology Challenge to help close this gap.

The Technology Challenge was a self-directed training program requiring participants to explore new technology on their own by spending at least fifteen minutes each day learning new technology skills. This program was successful in promoting lifelong learning by teaching technology applicable to the work and home lives of HBLL employees. We will first discuss literature that shows how technology training can help academic librarians connect with student patrons, and then we will describe the Technology Challenge and demonstrate how it aligns with the principles of self-directed learning. The training will be evaluated by an analysis of the results of two surveys given to participants before and after the Technology Challenge was implemented.

\section{Library 2.0 and "Librarian 2.0"}

HBLL wasn't the first to notice the gap between librarians and students, McDonald and Thomas noted that "Gaps have materialized," and library technology does not always "provide certain services, resources, or possibilities expected by emerging user populations like the millennial generation."1 College students, who grew up with technology, are "digital natives," while librarians, many having learned technology later in life, are "digital immigrants." ${ }^{2}$ The "digital natives" belong to the Millennial Generation, described by Shish and Allen as a generation of "learners raised on and confirmed experts in the latest, fastest, coolest, greatest, newest electronic technologies. ${ }^{\prime 3}$ According to Sweeny, when students use libraries, they expect the same "flexibility, geographic independence, speed of response, time shifting, interactivity, multitasking, and time savings" provided by the technology they use daily. ${ }^{4}$ Students are

Kayla L. Quinney (quinster27@gmail.com) is Research Specialist, Sara D. Smith (saradsmith@gmail.com) is Research Specialist, and Quinn Galbraith (quinn_galbraith@byu.edu) is Library Human Resource Training and Development Manager, Brigham Young University Library, Provo, Utah. 
masters of "informal learning"; that is, they are accustomed to easily and quickly gathering information relevant to their lives from the internet and from friends. Shish and Allen claimed that Millennials prefer "interactive, hyper-linked multimedia over the traditional static, textoriented printed items. They want a sense of control; they need experiential and collaborative approaches rather than formal, librarian-guided, library-centric services." ${ }^{5}$ These students arrive on campus expecting "to handle the challenges of scholarly research" using similar methods and technologies. ${ }^{6}$

Interactive technologies such as blogs, wikis, streaming media applications, and social networks, are referred to as "Web 2.0." Abram argued that Web 2.0 technology "could be useful in an enterprise, institutional research, or community environment, and could be driven or introduced by the library." "Library 2.0 " is a concept referring to a library's integration of these technologies; it is essentially the use of "Web 2.0 opportunities in a library environment." 8 Manesss described Library 2.0 is user-centered, social, innovative, and provider of a multimedia experiences. ${ }^{9}$ It is a community that "blurs the line between librarian and patron, creator and consumer, authority and novice." 10 Libraries have been using Web 2.0 technology such as blogs, ${ }^{11}$ wikis, ${ }^{12}$ and social networks ${ }^{13}$ to better serve and connect with patrons. Blogs allow libraries to "provide news, information and links to internet resources,"14 and wikis create online study groups ${ }^{15}$ and "build a shared knowledge repository."16 Social networks can be particularly useful in connecting with undergraduate students: Millennials use technology to collaborate and make collective decisions, ${ }^{17}$ and libraries can capitalize on this tendency by using social networks, which for students would mean, as Bates argues, "an informational equivalent of the reliance on one's Facebook friends."18

Students expect Library 2.0-and as libraries integrate new technologies, the staff and faculty of academic libraries need to become "Librarian 2.0." According to Abram, Librarian 2.0 understands users and their needs "in terms of their goals and aspirations, workflows, social and content needs, and more. Librarian 2.0 is where the user is, when the user is there."19 The modern library user "needs the experience of the Web ... to learn and succeed,"20 and the modern librarian can help patrons transfer technology skills to information seeking. Librarian 2.0 is prepared to help patrons familiar with Web 2.0 to "leverage these [technologies] to make a difference in reaching their goals." 21 Therefore staff and faculty "must become adept at key learning technologies themselves." 22 Stephen Abram asked, "Are the expectations of our users increasing faster than our ability to adapt?"23 and this same concern motivated HBLL and other institutions to initiate staff technology training programs.

The Public Library of Charlotte and Mecklenburg County of North Carolina (PLCMC) developed "Learning
2.0," a program that "focuses on self-exploration and encourages staff to learn about new technologies on their own." 24 Learning 2.0 encouraged library staff to explore Web 2.0 tools by completing twenty-three exercises involving new technologies. PLCMC's program has been replicated by more than 250 libraries and organizations worldwide, ${ }^{25}$ and several libraries have written about their experiences, including academic ${ }^{26}$ and public libraries. ${ }^{27}$

These programs-and the Technology Challenge implemented by HBLL-integrate the theories of adult learning. In the 1960s and 1970s, Malcolm Knowles introduced the theory of andragogy to describe the way adults learn. ${ }^{28}$ Knowles described adults as learners who (1) are self-directed, (2) use their experiences as a resource for learning, (3) learn more readily when they experience a need to know, (4) seek immediate application of knowledge, and (5) are best motivated by internal rather than external factors. ${ }^{29}$ The theory and practice of self-directed learning grew out of the first learning characteristic and assumes that adults prefer self-direction in determining and achieving learning goals, and therefore learners exercise independence in determining how and what they learn. ${ }^{30}$ These theories have had a considerable effect on adult education practice ${ }^{31}$ and employee development programs. ${ }^{32}$ When adults participate in trainings that align with the assumptions of andragogy, they are more likely to retain and apply what they have learned. ${ }^{33}$

\section{The Technology Challenge}

HBLL's Technology Challenge is similar to Learning 2.0 in that it encourages self-directed exploration of Web 2.0 technologies, but it differs in that participants were even more self-directed in exploration and that they were asked to participate daily. These features encouraged more self-directed learning in areas of participant interest as well as habit formation. It is not our purpose to critique Learning 2.0, but to provide some evidence and analysis to demonstrate the success of hands-on, self-directed training approaches and to suggest other ways for libraries to apply self-directed learning to technology training.

The Technology Challenge was implemented from June 2007 to January 2008. HBLL staff included 175 full-time employees, 96 of whom participated in the challenge. (The student employees were not involved.) Participants were asked to spend fifteen minutes each day learning a new technology skill. HBLL leaders used rewards to make the program enjoyable and to motivate participation: For each minute spent learning technology, participants earned one point, and when one thousand points were earned, the participant would receive a gift certificate to the campus bookstore. Staff and faculty participated and tracked their progress through an online 
board game called "Techopoly."

Participation was voluntary, and staff and faculty were free to choose which tasks and challenges they would complete. Tasks fell into one of four categories: software, hardware, library technology, and the internet. Participants were required to complete one hundred points in each category, but beyond that, were able to decide how to spend their time. Examples of tasks included attending workshops, exploring online tutorials, and reading books or articles about a relevant topic. For each hundred points earned, participants could complete a mini-challenge, which included reading blogs or e-books, listening to podcasts, or creating a photo CD (see appendix A for a more complete list). Participants who completed fifteen out of twenty possible challenges were entered into a drawing for another gift certificate.

Before beginning the Challenge, all participants were surveyed about their current use of technology. On this survey, they indicated that they were most uncomfortable with blogs, wikis, image editors, and music players. These results provided a focus for Technology Challenge trainings and mini-challenges. While not all of these technologies may apply directly to their jobs, 60 percent indicated that they were interested in learning them. Forty-four percent reported that time was the greatest impediment to learning new technology; therefore the daily fifteen-minute requirement was introduced with the hope that it was small enough to be a good incentive to participate but substantial enough to promote habit formation and allow employees enough time to familiarize themselves with the technology. Although some productivity may have been lost due to the time requirement (especially in cases where participants may have spent more than the required time), library leaders felt that technology training was an investment in HBLL employees and that, at least for a few months, it was worth any potential loss in productivity. Because participants could chose how and when they learned technology, they could incorporate the Challenge into their work schedules according to their own needs, interests, and time constraints.

Of ninety-six participants, sixty-six reached or exceeded the thousand-point goal, and eight participants earned more than two thousand points. Ten participants earned between five hundred and one thousand points, and another six earned between one hundred and five hundred. Although not all participants completed the Challenge, most were involved to some extent in learning technology during this time.

\section{The Technology Challenge and Adult Learning}

After finishing the Challenge, participants took an exit survey to evaluate the experience and report changes in their ability to learn and use technology. To be eligible to receive the gift card, participants were required to take this exit survey. Sixty-four participants, all of whom had met or exceeded the thousand-point goal, chose to complete this survey, so the results of this survey represent the experiences of 66 percent of the participants. Of course, if those who had not completed the Technology Challenge had taken the survey the results may have been different, but the results do show how those who chose to actively participate reacted to this training program. The survey included both quantifiable and open-ended questions (see appendix B for survey results and a list of the open-ended questions). The survey results, along with an analysis of the structure of the Challenge itself, demonstrates that the program aligns with Knowles's five principles of andragogy to successfully help employees develop both technology skills and learning habits.

\section{Self-direction}

The Technology Challenge was self-directed because it gave participants the flexibility to select which tasks and challenges they would complete. Garrison wrote that in a self-directed program, "learners should be provided with choices of how they wish to proactively carry out the learning process. Material resources should be available, approaches suggested, flexible pacing accommodated, and questioning and feedback provided when needed." ${ }^{34} \mathrm{HBLL}$ provided a variety of challenges and training sessions related to various technologies. Technology Challenge participants were given the independence to choose which learning methods to use, including which training sessions to attend and which challenges to complete.

According to the exit survey, the most popular training methods were small, instructor-led groups, followed by self-learning through reading books and articles. Group training sessions were organized by HBLL leadership and addressed topics such as Microsoft Office, RSS feeds, computer organization skills, and multimedia software. Other learning methods included web tutorials, DVDs, large group discussions, and one-on-one tutoring. The group training classes preferred by HBLL employees may be considered more teacher-directed than self-directed, but the Technology Challenge was self-directed as a whole in that learners were given the opportunity to choose what they learned and how they learned it.

The structure of the Technology Challenge allowed participants to set their own pace. Staff and faculty were given several months to complete the challenge and were responsible to pace themselves. On the exit survey, one participant commented: "If I didn't get anything done one week, there wasn't any pressure." Another enjoyed flexibility in deciding when and where to complete the tasks: "I liked being able to do the challenge anywhere. When I had a few minutes between appointments, classes, 
or meetings I could complete some of the challenges." Employees could also determine how much or how little of the Challenge they wanted to complete: many reached well over the thousand-point goal, while others fell a little short. Participants began at different skill levels, and thus could use the time and resources allotted to explore basic or more advanced topics according to their needs and interests.

Garrison had noted the importance of providing resources and feedback in self-directed learning. ${ }^{35}$ The Techopoly website provided resources (such as specific blogs or websites to visit) and instructions on how to use and access technology within the library. HBLL also hired a student to assist staff and faculty one-on-one by explaining answers to their questions about technology and teaching other skills he thought may be relevant to their initial problem. The entrance and exit surveys provided opportunities for self-reflection and self-evaluation by questioning the participants' use of technology before the Challenge and asking them to evaluate their proficiency in technology after the Challenge.

\section{Use of Experience}

The use of experience as a source of learning is important to adult learners: "The richest resource for learning resides in adults themselves; therefore, tapping into their experiences through experiential techniques (discussions, simulations, problem-solving activities, or case methods) is beneficial." ${ }^{\prime 36}$ The small-group discussions and one-onone problem solving made available to HBLL employees certainly fall into these categories. Small-group classes are one of the best ways to encourage adults to share and validate their experiences, and doing so increases retention and application of new information. ${ }^{37}$ The trainings and challenges encouraged participants to make use of their work and personal experiences by connecting the topic to work or home application. For example, one session discussed how blogs relate to libraries, and another helped participants learn Adobe Photoshop skills by editing personal photographs.

\section{Need to Know}

Adult learners are more successful when they desire and recognize a need for new knowledge or skills. The role of a trainer is to help learners recognize this "need to know" by "mak[ing] a case for the value of learning." ${ }^{38}$ HBLL used the generational survey and presurvey to develop a need and desire to learn. The results of the generational survey, which demonstrated a gap in technology use between librarians and students, were presented and discussed at a meeting held before the initiation of the Technology Challenge to help staff and faculty understand why it was important to learn 2.0 technology. Results of the presurvey showed that staff and faculty were willing, even excited, to learn technology skills: 37 percent "agreed" and 60 percent "strongly agreed" that they were interested in learning new technology. Their desire to learn was cultivated by the survey itself, which helped them recognize and focus on this interest, and the Challenge provided a way for employees to channel their desire to learn technology.

\section{Immediate Application}

Learners need to see an opportunity for immediate application of their knowledge: Ota et al. explained that "they want to learn what will help them perform tasks or deal with problems they confront in everyday situations and those presented in the context of application to real life." ${ }^{39}$ Because of the need for immediate application, the Technology Challenge encouraged staff and faculty to learn technology skills directly related to their jobs-as well as technology that is applicable to their personal or home lives. HBLL leaders hoped that as staff became more comfortable with technology in general, they would be motivated to incorporate more complex technologies into their work.

Here is one example of how the Technology Challenge catered to adult learners' need to apply what they learn: Before designing the Challenge, HBLL held a training session to teach employees the basics of Photoshop. Even though attendees were on the clock, the turnout was discouraging. Library leaders knew they needed to try something new. In the revamped Photoshop workshop that was offered as part of the Technology Challenge, attendees brought family photos or film and learned how to edit and experiment with their photos and burn DVD copies. This time, the class was full: the same computer program that before drew only a few people was now exciting and useful. Focusing on employees' personal interests in learning new software, instead of just on teaching the software, better motivated staff and faculty to attend the training.

\section{Motivation}

As stated by Ota et al., adults are motivated by external factors but are usually more motivated by internal factors: "Adults are responsive to some external motivators (e.g., better job, higher salaries), but the most potent motivators are internal (e.g., desire for increased job satisfaction, self-esteem)." 40 On the entrance survey, participants were given the opportunity to comment on their reasons for participating in the Challenge. The gift card, an example of an external motivation, was frequently cited as an important motivation. But many also commented on more internal motivations: "It's important to my job to stay proficient in new technologies and I'd like to stay current"; "I feel that I need to be up-to-date 
on technology in order to effectively help patrons"; "to identify and become comfortable with new technologies that will make my work more efficient, more presentable, and more accurate."

\section{Lifelong Learning}

Staff and faculty responded favorably to the training. None of the participants who took the exit survey disliked the challenge; 34 percent even reported that they strongly liked it. Ninety-five percent reported that they enjoyed the process of learning new technology, and 100 percent reported that they were willing to participate in another technology challenge- thus suggesting success in the goal of encouraging lifelong technology learning.

The exit survey results indicate that after completing the challenge, staff and faculty are more motivated to continue learning - which is exactly what HBLL leaders hoped to accomplish. Eighty-nine percent of the participants reported that their desire to learn new technology had increased, and 69 percent reported that they are now able to learn new technology faster after completing the Technology Challenge. Ninety-seven percent claimed that they were more likely to incorporate new technology into home or work use, and 98 percent said they recognized the importance of staying on top of emerging technologies. Participants commented that the training increased their desire to learn. One observed, "I often need a challenge to get motivated to do something new," and another participant reported feeling "a little more comfortable trying new things out."

The exit survey asked participants to indicate how they now use technology. One employee keeps a blog for her daughter's dance company, and another said, "I'm on my way to a full-blown GoogleReader addiction." Another participant applied these new skills at home: "I'm not so afraid of exploring the computer and other software programs. I even recently bought a computer for my own personal use at home." The Technology Challenge was also successful in helping employees better serve patrons: "I can now better direct patrons to services that I would otherwise not have known about, such as streaming audio and video and e-book readers." Another participant felt better connected to student patrons: "I understand the students better and the things they use on a daily basis."

Staff and faculty also found their new skills applicable to work beyond patron interaction, and many listed specific examples of how they now use technology at work:

- "I have attended a few Microsoft Office classes that have helped me tremendously in doing my work more efficiently, whether it is for preparing monthly statistical reports or working with colleagues from other libraries."

- "I learned how to set up a server that I now maintain on a semi-regular basis. I learned a lot about SFX and have learned some Perl programming language as well that I use in my job daily as I maintain SFX."

- "The new OCLC client was probably the most significant. I spent a couple of days in an online class learning to customize the client, and I use what I learned there every single day."

- "I use Google docs frequently for one of the projects I am now working on."

Participants also indicated weaknesses in the Technology Challenge. Almost 20 percent of those who completed the Challenge reported that it was too easy. This is a valid point-the Challenge was designed to be easy so as not to intimidate staff or faculty who are less familiar with technology. It is important to note that these comments came from those who completed the Challenge-other participants may have found the tasks and mini-challenges more difficult. The goal was to provide an introduction to Web 2.0, not to train experts. However, a greater range of tasks and challenges could be provided in the future to allow staff and faculty more selfdirection in selecting goals relevant to their experience.

To encourage staff and faculty to attend sponsored training sessions as part of the Challenge, HBLL leaders decided to double points for time spent at these classes. This certainly encouraged participation, but it lead to "point inflation"-perhaps being one reason why so many reported that the Challenge was too easy to complete. The doubling of points may also have encouraged staff to spend more time in workshops and less time practicing or applying the skills learned. A possible solution would be offering 1.5 points, or offering a set number of points for attendance instead of counting per minute.

It also may have been informative for purpose of analysis to have surveyed both those who did not complete the Challenge as well as those who chose not to participate. Because the presurvey indicated that time was the biggest deterrent to learning and incorporating new technology, we assume that many of those who did not participate or who did not complete the challenge felt that they did not have enough time to do so. There is definitely potential for further investigation into why library staff would not want to participate in a technology training program, what would motivate them to participate, and how we could redesign the Technology Challenge to make it more appealing to all of our staff and faculty.

Several library employees have requested that HBLL sponsor another Technology Challenge program. Because of the success of the first and because of continuing interest in technology training, we plan to do so in the future. We will make changes and adjustments according to the 
feedback we have received, and continue to evaluate it and improve it based on survey results. The purpose of a second Technology Challenge would be to reinforce what staff and faculty have already learned, to teach new skills, and to help participants remember the importance of lifelong learning when it comes to technology.

\section{Conclusion}

HBLL's self-directed Technology Challenge was successful in teaching technology skills and in promoting lifelong learning-as well as in fostering the development of Librarian 2.0. Abram listed key characteristics and duties of Librarian 2.0, including learning the tools of Web 2.0; connecting people, technology, and information; embracing "nontextual information and the power of pictures, moving images, sight, and sound"; using the latest tools of communication; and understanding the "emerging roles and impacts of the blogosphere, Web syndicasphere, and wikisphere." 41 Survey results indicated that HBLL employees are on their way to developing these attributes, and that they are better equipped with the skills and tools to keep learning.

Like PLCMC's Learning 2.0, the Technology Challenge could be replicated in libraries of various sizes. Obviously an exact replication would not be feasible or appropriate for every library-but the basic ideas, such as the principles of andragogy and self-directed learning could be incorporated, as well as the daily time requirement or the use of surveys to determine weaknesses or interests in technology skills. Whatever the case, there is a great need for library staff and faculty to learn emerging technologies and to keep learning them as technology continues to change and advance.

But the most important benefit of a self-directed training program focusing on lifelong learning is effective employee development. The goal of any training program is to increase work productivity-and as employees become more productive and efficient, they are happier and more excited about their jobs. On the exit survey, one participant expressed initially feeling hesitant about the Technology Challenge and feared that it would increase an already hefty workload. However, once the Challenge began, the participant enjoyed "taking the time to learn about new things. I feel I am a better person/librarian because of it." And that, ultimately, is the goal-not only to create better librarians, but also to create better people.

\section{Notes}

1. Robert H. McDonald and Chuck Thomas, "Disconnects between Library Culture and Millennial Generation Values," Educause Quarterly 29, no. 4 (2006): 4.
2. Richard T. Sweeny, "Reinventing Library Buildings and Services for the Millennial Generation," Library Administration $\mathcal{E}$ Management 19, no. 4 (2005): 170.

3. Win Shish and Martha Allen, "Working with GenerationD: Adopting and Adapting to Cultural Learning and Change," Library Management 28, no. 1/2 (2006): 89.

4. Sweeney, "Reinventing Library Buildings," 170.

5. Shish and Allen, "Working with Generation-D," 96.

6. Ibid., 98 .

7. Stephen Abram, "Social Libraries: The Librarian 2.0 Pheonomenon," Library Resources \& Technical Services 52, no. 2 (2008): 21.

8. Ibid.

9. Jack M. Maness "Library 2.0 Theory: Web 2.0 and Its Implications for Libraries," Webology 3, no. 2 (2006), http:// www.webology.ir/2006/v3n2/a25.html?q=link:webology.ir/ (accessed Jan. 8, 2010).

10. Ibid., under "Blogs and Wikis," para. 4.

11. Laurel Ann Clyde, "Library Weblogs," Library Management 22, no. 4/5 (2004): 183-89; Maness, "Library 2.0. Theory."

12. See Matthew M. Bejune, "Wikis in Libraries," Information Technology E Libraries 26, no. 3 (2007): 26-38 ; Darlene Fichter, "The Many Forms of E-Collaboration: Blogs, Wikis, Portals, Groupware, Discussion Boards, and Instant Messaging," Online: Exploring Technology \& Resources for Information Professionals 29, no. 4 (2005): 48-50; Maness, "Library 2.0 Theory."

13. Mary Ellen Bates, "Can I Facebook That?" Online: Exploring Technology and Resources for Information Professionals 31, no. 5 (2007): 64; Sarah Elizabeth Miller and Lauren A. Jensen, "Connecting and Communicating with Students on Facebook," Computers in Libraries 27, no. 8 (2007): 18-22.

14. Clyde, "Library Weblogs," 183.

15. Maness, "Library 2.0 Theory."

16. Fichter, "Many Forms of E-Collaboration," 50.

17. Sweeney, "Reinventing Library Buildings"; Bates, "Can I Facebook That?"

18. Bates, "Can I Facebook That?" 64.

19. Abram, "Social Libraries," 21.

20. Ibid., 20.

21. Ibid., 21.

22. Shish and Allen, "Working with Generation-D," 90

23. Abram, "Social Libraries," 20.

24. Helene Blowers and Lori Reed, "The C's of Our Sea Change: Plans for Training Staff, from Core Competencies to Learning 2.0," Computers in Libraries 27, no. 2 (2007): 11.

25. Helene Blowers, Learning 2.0, 2007, http:// plcmclearning .blogspot.com (accessed Jan. 8, 2010).

26. For examples, see Ilana Kingsley and Karen Jensen, "Learning 2.0: A Tool for Staff training at the University of Alaska Fairbanks Rasmuson," The Electronic Journal of Academic $\mathcal{E}$ Special Librarianship 12, no. 1 (2009), http://southernlibrarianship.icaap.org/content/v10n01/kingsley_i01.html (accessed Jan. 8, 2010); Beverly Simmons, "Learning (2.0) to be a Social Library," Tennessee Libraries 58, no. 2 (2008): 1-8.

27. For examples, see Christine Mackenzie, "Creating our Future: Workforce Planning for Library 2.0 and Beyond," Australasian Public Libraries E Information Services 20, no. 3 (2007): 118-24; Liisa Sjoblom, "Embracing Technology: The Deschutes Public Library's Learning 2.0 Program," OLA Quarterly 14, no. 2 (2007): 2-6; Hui-Lan Titango and Gail L. Mason, "Learning Library 2.0: 23 Things @ SCPL," Library Management 30, no. 1/2 
(2009): 44-56; Illinois Library Association, "Continuous Improvement: The Transformation of Staff Development," The Illinois Library Association Reporter 26, no. 2 (2008): 4-7; and Thomas Simpson, "Keeping up with Technology: Orange County Library Embraces 2.0," Florida Libraries 20, no. 2 (2007): 8-10.

28. Sharan B. Merriam, "Andragogy and Self-Directed Learning: Pillars of Adult Learning Theory," New Directions for Adult $\mathcal{E}$ Continuing Education 89 (2001): 3-13.

29. Malcolm Shepherd Knowles, The Modern Practice of Adult Education: From Pedagogy to Andragogy (New York: Cambridge Books, 1980).

30. Jovita Ross-Gordon, "Adult Learners in the Classroom," New Directions for Student Services 102 (2003): 43-52.

31. Merriam, "Pillars of Adult Learning"; Ross-Gordon, "Adult Learners."

32. Carrie Ota et al., "Training and the Needs of Learn- ers," Journal of Extension 33 (2005), http://www.joe.org/ joe/2006december/tt5.php (accessed Jan. 8, 2010); Wayne G. West, "Group Learning in the Workplace," New Directions for Adult and Continuing Education 71 (1996): 51-60.

33. Ota et al., "Needs of Learners."

34. D. R. Garrison, "Self-directed Learning: Toward a Comprehensive Model," Adult Education Quarterly 48 (1997): 22.

35. Ibid.

36. Ota et al., "Needs of Learners," under "Needs of the Adult Learner," para. 4.

37. Ota et al., "Needs of Learners"; West, "Group Learning."

38. Ota et al., "Needs of Learners," under "Needs of the Adult Learner," para. 2.

39. Ibid., para. 6

40. Ibid., para 7.

41. Abram, "Social Library," 21-22.

\section{Appendix A. Technology Challenge "Mini Challenges"}

Technology Challenge participants had the opportunity to complete fifteen of twenty mini-challenges to become eligible to win a second gift certificate to the campus bookstore. Below are some examples of technology mini-challenges:

1. Read a library or a technology blog

2. Listen to a library podcast

3. Check out a book from Circulation's new self-checkout machine

4. Complete an online copyright tutorial

5. Catalog some books on LibraryThing

6. Read an e-book with Sony eBook Reader or Amazon Kindle

7. Scan photos or copy them from a digital camera and then burn them onto a $\mathrm{CD}$

8. Backup data

9. Change computer settings

10. Schedule meetings with Microsoft Outlook

11. Create a page or comment on a page on the library's intranet wiki

12. Use one of the library's music databases to listen to music

13. Use WordPress or Blogger to create a blog

14. Post a photo on a blog

15. Use Google Reader or Bloglines to subscribe to a blog or news page using RSS

16. Reserve and check out a digital camera, camcorder, DVR, or slide scanner from the multimedia lab and create something with it

17. Convert media on the analog media racks

18. Edit a family photograph using photo-editing software

19. Attend a class in the multimedia lab

20. Make a phone call using Skype 


\section{Appendix B. Exit Survey Results}

\begin{tabular}{lcc}
\hline $\begin{array}{l}\text { How did you like the Technology Challenge } \\
\text { overall? }\end{array}$ & & \\
\hline Answer & Response & Percent \\
Strongly disliked & 0 & 0 \\
Disliked & 0 & 0 \\
Liked & 42 & 66 \\
Strongly liked & 22 & 34 \\
\hline
\end{tabular}

How did you like the reporting system used for the Technology Challenge (the Techopoly Game)?

\begin{tabular}{lcc}
\hline Answer & Response & Percent \\
Strongly disliked & 0 & 0 \\
Disliked & 4 & 6 \\
Liked & 41 & 64 \\
Strongly liked & 19 & 30 \\
\hline \multicolumn{3}{l}{} \\
\hline \multicolumn{3}{l}{ Would you participate in another Technology } \\
Challenge? & \multicolumn{2}{|}{} \\
\hline Answer & Response & Percent \\
Yes & 64 & 100 \\
No & 0 & 0 \\
\hline
\end{tabular}

What percentage of time did you spend using the following methods of learning? (participants were asked to allocate 100 points among the categories)

\begin{tabular}{lc}
\hline Category & Average Response \\
Instructor-led large group & 15.3 \\
Instructor-led small group & 27 \\
One-on-one instruction & 3.5 \\
Web tutorial & 12.8 \\
Self-learning (books, & 27.4 \\
articles) & .5 \\
DVDs & 2.7 \\
Small group discussion & 2.6 \\
Large group discussion & 6.7 \\
Other & \\
\hline
\end{tabular}

I am more likely to incorporate new technology into my home or work life.

\begin{tabular}{lcc}
\hline Answer & Response & Percent \\
Strongly disagree & 0 & 0 \\
Disagree & 2 & 3 \\
Agree & 49 & 77 \\
Strongly agree & 13 & 20 \\
\hline
\end{tabular}

I enjoy the process of making new technology a part of my work or home life.

\begin{tabular}{lcc}
\hline Answer & Response & Percent \\
Strongly disagree & 0 & 0 \\
Disagree & 2 & 3 \\
Agree & 37 & 58 \\
Strongly agree & 24 & 38 \\
\hline
\end{tabular}

After completing the Technology Challenge, my desire to learn new technologies has increased.

\begin{tabular}{lcc}
\hline Answer & Response & Percent \\
Strongly disagree & 0 & 0 \\
Disagree & 7 & 11 \\
Agree & 44 & 69 \\
Strongly agree & 13 & 20 \\
\hline
\end{tabular}

I feel I now learn new technologies more quickly.

\begin{tabular}{lcc}
\hline Answer & Response & Percent \\
Strongly disagree & 0 & 0 \\
Disagree & 20 & 31 \\
Agree & 39 & 61 \\
Strongly agree & 5 & 8 \\
\hline
\end{tabular}




\begin{tabular}{lccr}
\hline How much more proficient do you feel in . . . \\
\hline Category & Not any & Somewhat & A lot \\
Hardware & $31 \%$ & $64 \%$ & $5 \%$ \\
Software & $8 \%$ & $72 \%$ & $20 \%$ \\
Internet resources & $17 \%$ & $68 \%$ & $15 \%$ \\
Library & $23 \%$ & $64 \%$ & $13 \%$ \\
technology & & & \\
\hline
\end{tabular}

\section{Open-Ended Questions}

- What would you change about the technology challenge?

- What did you like about the Technology Challenge?

- What technologies were you introduced to during the Technology Challenge that you now use on a regular basis?

- In what was do you feel the Technology Challenge has benefited you the most?

In order for you to succeed in your job, how important is keeping abreast of new technologies to you?

\begin{tabular}{lcc}
\hline Answer & Response & Percent \\
Not important & 1 & 2 \\
Important & 22 & 34 \\
Very important & 41 & 64 \\
\hline
\end{tabular}

